\title{
Chemical Redox-Cycling for Improving the Sensitivity of Colorimetric Enzyme-Linked Immunosorbent Assay
}

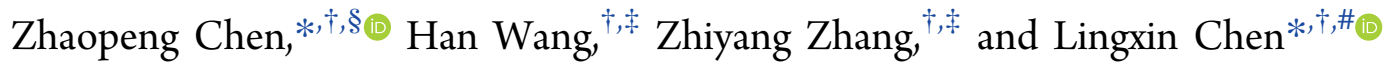 \\ ${ }^{\dagger}$ CAS Key Laboratory of Coastal Environmental Processes and Ecological Remediation, Yantai Institute of Coastal Zone Research \\ (YIC), Chinese Academy of Sciences(CAS) and Shandong Provincial Key Laboratory of Coastal Environmental Processes, \\ YICCAS, Yantai, Shandong 264003, P. R. China \\ ${ }^{\S}$ Department of Applied Chemistry, School of Science, Xi'an University of Technology, Xi'an 710061, P. R. China \\ "Laboratory for Marine Biology and Biotechnology, Pilot National Laboratory for Marine Science and Technology, Qingdao \\ 266237, P.R. China \\ ${ }^{\ddagger}$ University of Chinese Academy of Sciences, Beijing 100049, P. R. China
}

\section{Supporting Information}

\begin{abstract}
Herein, a redox-cycling was proposed to amplify the signal of enzyme-linked immunosorbent assay (ELISA), which was performed in a polystyrene microplate based on a classic sandwich-type. After the sandwich immunoreactions were finished, the alkaline phosphatase captured on a microplate triggered the hydrolyzation of L-ascorbic acid 2-phosphate to generate ascorbic acid (AA), which then reduced colorless tris(bathophenanthroline) iron(III) $\left(\mathrm{Fe}(\mathrm{BPT}){ }_{3}{ }^{3+}\right.$ ) encapsulated in the micelle of TX-100 to pink red tris(bathophenanthroline) iron(II) $\left(\mathrm{Fe}(\mathrm{BPT})_{3}{ }^{2+}\right)$. In the presence of tris(2-carboxyethyl)phosphine, the oxidation product, dehydroascorbic acid, was transformed to AA quickly which then reduced $\mathrm{Fe}(\mathrm{BPT}){ }_{3}{ }^{3+}$ again and again, resulting in the generation of abundant $\mathrm{Fe}(\mathrm{BPT})_{3}{ }^{2+}$ that

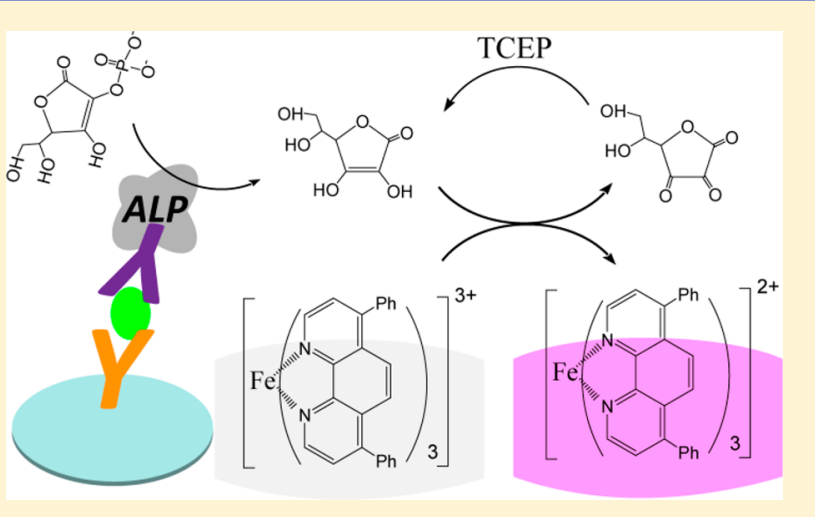
could be read out conveniently by a commercial microplate reader or the naked eye. Because the negative charged TCEP with large size could hardly pass through the micelle, the reduction of $\mathrm{Fe}(\mathrm{BPT})_{3}{ }^{3+}$ by TCEP directly was negligible. Experiment results for assay of alpha-fetoprotein (a model antigen) showed the cycling greatly improved the detection limit to $5 \mathrm{pg} / \mathrm{mL}, 2$ orders of magnitude lower than that of conventional ELISA. The cycling also exhibited the advantages of simplicity and high reproducibility, implying its great potential for practical applications in biological and clinical diagnosis.
\end{abstract}

$\mathrm{O}$ wing to its simplicity, low-cost, easy operation, and control, enzyme-linked immunosorbent assay (ELISA) based on UV-vis spectroscopic detection has become a powerful biochemical testing tool and has been widely applied to food quality control, ${ }^{1}$ environmental monitoring, ${ }^{2}$ and clinical diagnosis. ${ }^{3,4}$ Nevertheless, suffering from the low sensitivity of UV-vis spectroscopic detection for colored molecules generated by enzyme catalysis, conventional ELISA using a microplate reader as the signal detector has a relatively low sensitivity, normally ranging from $\mu \mathrm{g} / \mathrm{mL}$ to $\mathrm{ng} / \mathrm{mL}$, 5,6 which cannot meet the ever-growing demand of early disease diagnosis based on low-abundance biomarkers. To solve this problem, various signal amplification techniques (biotinavidin system, ${ }^{7}$ tyramide signal amplification, ${ }^{8}$ cascade signal amplification, ${ }^{9}$ DNA hybridization chain reaction, ${ }^{10}$ etc.), enzyme-loaded particles labeling techniques (liposomes, ${ }^{11,12}$ gold nanoparticles, ${ }^{13}$ polystyrene microparticles, ${ }^{14}$ micrometersized magnetic particles, ${ }^{15}$ silica nanoparticles, ${ }^{16,17}$ nanospherical brushes, ${ }^{18}$ etc.), and methods based on sensitive detection of enzyme-catalyzed products (plasmonic
ELISA, ${ }^{19,20}$ enzyme-assisted cofactor-recycling amplification, ${ }^{21}$ etc.) have been proposed to improve the sensitivity of ELISA. Although most of these methods are effective and some of them even have drastically pushed the detection limit almost 2 orders of magnitude lower than that of conventional ELISA, the cumbersome analysis process or labeling procedure has hindered their further popularization.

Catalytic spectrophotometry, also named target cycling amplification, has proved to be sensitive for determination of target analyte. ${ }^{22}$ In this method, the target analyte acts as a catalyst to accelerate the color development reaction, leading to the generation of abundant colored molecules in a short period and therefore the signal is amplified. To date, this method has been widely applied to the determination of metal ions and a few organic molecules. Theoretically, the sensitivity

Received: November 5, 2018

Accepted: December 17, 2018

Published: December 17, 2018 
of ELISA can be improved by developing cycling amplification for sensing of enzyme-catalyzed product. To achieve this aim, enzyme-assisted cofactor-recycling amplification has been proposed for ELISA, promoting the sensitivity about 2 orders of magnitude. ${ }^{21}$ The method seems time-consuming, and the additional introduction of enzyme increased the cost of ELISA.

Recent reports show that some enzyme-catalyzed products, such as ascorbic acid (AA), $p$-aminophenol, and hydroquinone, can be detected sensitively via an electrochemical assay based on redox-cycling amplification in the presence of tris(2carboxyethyl)phosphine (TCEP), nicotinamide adenine dinucleotide $(\mathrm{NADH})$, and so on. In this strategy, the enzymecatalyzed product on the surface of the electrode was first oxidized electrochemically to its corresponding oxidation state, which was then reduced to its initial state by reductants. The electrochemical signal was therefore enhanced. ${ }^{23-26}$

Inspired by the electrochemical redox-cycling amplification mentioned above, herein we reported an ultrasensitive colorimetric immunoassay system based on sensitive determination of $\mathrm{AA}$, an enzyme-catalyzed product of alkaline phosphatase (ALP), by using a simple chemical redox-cycling amplification. The system greatly improved the sensitivity of ELISA by over 2 orders of magnitude.

Scheme 1 outlines principle of the redox-cycling-based colorimetric ELISA. The ELISA for alpha-fetoprotein (AFP)

Scheme 1. Principle of the Redox-Cycling-Based

Colorimetric ELISA

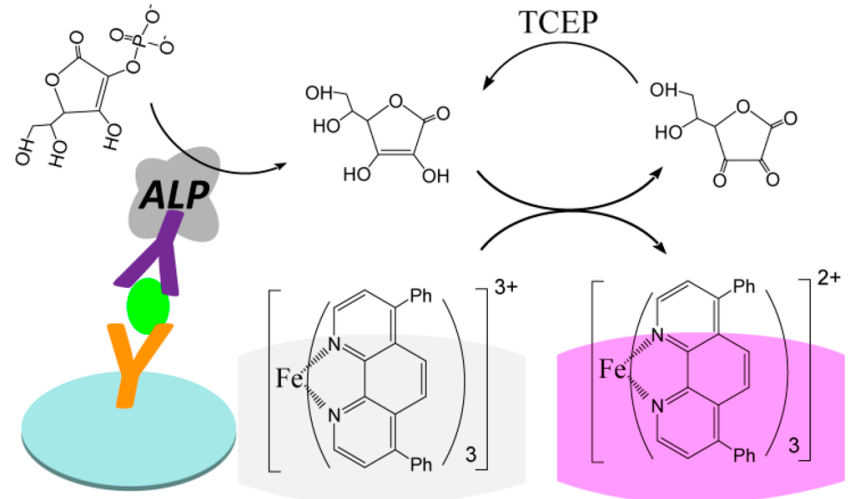

detection was performed in a polystyrene microplate by using a classic sandwich type. ALP tagged antibody was captured on the microplate, and then it triggered the hydrolyzation of Lascorbic acid 2-phosphate to generate AA. The reaction between AA and colorless tris(bathophenanthroline) iron(III) $\left(\mathrm{Fe}(\mathrm{BPT}){ }_{3}{ }^{3+}\right)$ resulted in the generation of pink red tris(bathophenanthroline) iron(II) $\left(\mathrm{Fe}(\mathrm{BPT})_{3}{ }^{2+}\right.$ ) and dehydroascorbic acid. The latter was then reduced to AA again simultaneously by TCEP. The cycling reaction produced abundant $\mathrm{Fe}(\mathrm{BPT})_{3}{ }^{2+}$ and therefore the colorimetric signal was amplified significantly. It should be noted here that the direct reduction of $\mathrm{Fe}(\mathrm{BPT}){ }_{3}{ }^{3+}$ by TCEP could hardly be perceived. The generated pink red $\mathrm{Fe}(\mathrm{BPT})_{3}{ }^{2+}$ was then monitored by the naked eye or a commercial microplate reader, and the concentration of the model antigen, AFP, was quantified indirectly.

\section{EXPERIMENTAL SECTION}

Chemicals and Apparatus. Ascorbic acid (AA), Triton X100 (TX-100), $\mathrm{FeCl}_{3} \cdot 6 \mathrm{H}_{2} \mathrm{O}, \mathrm{Na}_{2} \mathrm{HPO}_{4} \cdot 12 \mathrm{H}_{2} \mathrm{O}, \mathrm{NaH}_{2} \mathrm{PO}_{4}$.
$2 \mathrm{H}_{2} \mathrm{O}, \mathrm{Na}_{2} \mathrm{CO}_{3}, \mathrm{NaHCO}_{3}, \mathrm{Na}_{2} \mathrm{SO}_{3}$, and 1,10-phenanthroline (Phen) were obtained from Sinopharm Chemical Reagent Co., Ltd. (China). Hydroxylamine hydrochloride $\left(\mathrm{NH}_{2} \mathrm{OH} \cdot \mathrm{HCl}\right)$, reduced glutathione $(\mathrm{GSH}), \mathrm{NaBH}_{4}$ were bought from Aladdin Chemical Reagent Co., Ltd. (China). L-Ascorbic acid 2-phosphate (AA-p) and bovine serum albumin (BSA) were purchased from Sigma-Aldrich Corporation (America). 4,7Dipheny-1,10-phenanthroline (also named bathophenanthroline, BPT) and tris (2-carboxyethyl)phosphine hydrochloride (TCEP) were bought from Shanghai Macklin Biochemical Co., Ltd. (China). Alkaline phosphatase (ALP) was obtained from Dalian Meilun Biotechnology Company (Dalian, China). Dithiothreitol (DTT) and nicotinamide adenine dinucleotide $(\mathrm{NADH})$ were bought from Beijing Solarbio Science \& Technology Co., Ltd. (China). L-Cysteine was obtained from Xiya Chemical Industry Co., Ltd. (China). Carcinoembryonic antigen (CEA), immunoglobulin $\mathrm{G}$ ( $\operatorname{IgG})$, and prostate specific antigen (PSA) were purchased from Beijing Dingguo Changsheng Biotechnology Co., Ltd. Human alpha-fetoprotein (AFP) antigen purified was obtained from Shanghai Linc-Bio Science Co., Ltd. (China). Mouse anti-AFP (A2) monoclonal antibody, mouse anti-AFP (A4)/AP were purchased from Beijing Biosynthesis Biotechnology Company (China). The 96-well polystyrene microplates were bought from CorningCostar (America). AFP ELISA kit was purchased from Biocell Biotechnol. Co., Ltd. (China). All of the chemicals were analytical reagent grade or better. Solutions were all prepared with deionized water (18.2 M $\Omega$, Pall Corporation Cascada LS). UV-visible absorption spectra were measured on a spectrophotometer (Thermo Scientific NanoDrop 2000/ $2000 \mathrm{C}$ ) and a microplate reader (TECAN Infinite $200 \mathrm{M}$ PRO NanoQuant).

Procedure for AA Detection. The measurements were performed in a centrifuge tube. To $1000 \mu \mathrm{L}$ of $50 \mathrm{mM}$ $\mathrm{Na}_{2} \mathrm{HPO}_{4}$ solution containing different concentrations of $\mathrm{AA}$, $15 \mu \mathrm{L}$ of $100 \mathrm{mM}$ TCEP, $60 \mu \mathrm{L}$ of the prepared mixture solution of $\mathrm{FeCl}_{3}(10 \mu \mathrm{L}, 10 \mathrm{mM}), \mathrm{BPT}(20 \mu \mathrm{L}, 10 \mathrm{mM}$, dissolved in ethanol), and TX-100 $(30 \mu \mathrm{L}, 10 \%)$ were added in sequence. The mixed solutions were incubated at $50{ }^{\circ} \mathrm{C}$ for 10 min and then were measured by the UV-visible spectrophotometer at the wavelength of $534 \mathrm{~nm}$ (baseline $750 \mathrm{~nm}$ ).

Procedure for ALP Detection. A volume of $110 \mu \mathrm{L}$ of $\mathrm{Na}_{2} \mathrm{CO}_{3} / \mathrm{NaHCO}_{3}$ buffer solution (10 mM, pH 9.4) containing $1 \mathrm{mM}$ AA-p and different concentrations of ALP were added into the 96 -well polystyrene microplates and incubated at $37{ }^{\circ} \mathrm{C}$ for $60 \mathrm{~min}$. Then, $118 \mu \mathrm{L}$ of mix solution $\left(100 \mu \mathrm{L}\right.$ of $100 \mathrm{mM} \mathrm{Na}_{2} \mathrm{HPO}_{4}, 6 \mu \mathrm{L}$ of $50 \mathrm{mM}$ TCEP, $2 \mu \mathrm{L}$ of $10 \mathrm{mM} \mathrm{FeCl}_{3}, 4 \mu \mathrm{L}$ of $10 \mathrm{mM} \mathrm{BPT}$, and $6 \mu \mathrm{L}$ of $10 \% \mathrm{TX}-100$ ) was added into the wells. After incubation at $50{ }^{\circ} \mathrm{C}$ for $10 \mathrm{~min}$, the absorbance of the obtained solution was recorded at 534 $\mathrm{nm}$ by a microplate reader (reference $750 \mathrm{~nm}$ ).

Sandwich Enzyme-Based Immunoassay for AFP Detection. First, $100 \mu \mathrm{L}$ of $20 \mu \mathrm{g} / \mathrm{mL}$ mouse anti-AFP monoclonal antibody dissolved in $50 \mathrm{mM} \mathrm{NaHCO} / \mathrm{Na}_{2} \mathrm{CO}_{3}$ buffer ( $\mathrm{pH}$ 9.6) was added to the 96-well polystyrene microplates and incubated at $4{ }^{\circ} \mathrm{C}$ for $12 \mathrm{~h}$. After removing the solution, $200 \mu \mathrm{L}$ of $1 \%$ BSA solution (dissolved in $0.05 \mathrm{M}$ PBS, $\mathrm{pH}$ 7.4) was injected to block the active nonspecific binding sites of the wells at $37{ }^{\circ} \mathrm{C}$ for $1 \mathrm{~h}$. Then, $100 \mu \mathrm{L}$ of varied concentrations of human AFP antigen dissolved in 0.05 M PBS buffer ( $\mathrm{pH} 7.4,1 \%$ BSA) was added into the wells and incubated at $37^{\circ} \mathrm{C}$ for another $1 \mathrm{~h}$. Then, the wells were rinsed with $0.05 \mathrm{M}$ PBS solution ( $\mathrm{pH} 7.4,1 \% \mathrm{BSA}$ ) for eight times. 
Following this step, $100 \mu \mathrm{L}$ of ALP-conjugated antibody (1:500 dilution) was injected to the microwells and incubated at $37{ }^{\circ} \mathrm{C}$ for an additional hour. After the formation of the sandwich immunocomplex, the wells were rinsed with $0.05 \mathrm{M}$ PBS solution ( $\mathrm{pH} 7.4,1 \%$ BSA) for eight times. The captured ALP in the microwells was then quantified with the same procedure as the procedure for ALP detection.

For more experimental procedures and details please see pages S-3-S-5 (Supporting Information).

\section{RESULTS AND DISCUSSION}

Principle for the Redox-Cycling System. For the redoxcycling system developed for the first time to detect AA in this work, the mechanism is also discussed. As shown in the inset in Figure 1A, the absorbance of the solution consisting of TCEP (1.5 mM), TX-100, and $\mathrm{Fe}(\mathrm{BPT})_{3}{ }^{3+}$ at $534 \mathrm{~nm}$ increased slowly in the absence of AA (red dots), while with the presence of AA $(0.5 \mu \mathrm{M})$, the absorbance increased sharply as the
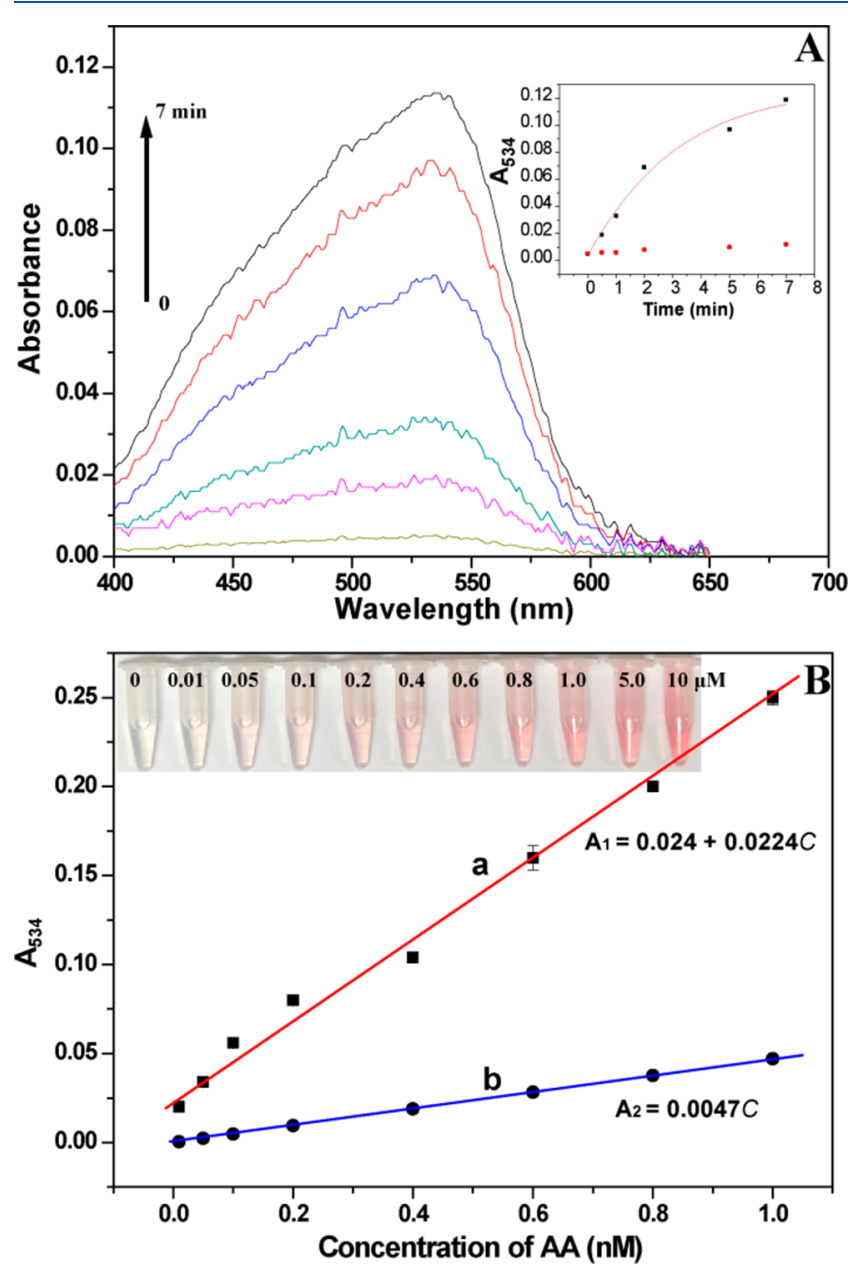

Figure 1. (A) Absorption spectra of the redox-cycling system response to $0.5 \mu \mathrm{M}$ of AA after incubation for different times. The inset in part A shows the absorbance at $534 \mathrm{~nm}$ of the redox-cycling system response to 0.5 (black dot) and $0 \mu \mathrm{M}$ (red dot) AA, respectively. (B) Absorbance at $534 \mathrm{~nm}$ (curve a in part B) and color (digital photo inset in part B) of the redox-cycling system response to different concentrations of AA. Curve $\mathrm{b}$ in part $\mathrm{B}$ is obtained according to stoichiometric reaction between $\mathrm{AA}$ and $\mathrm{Fe}(\mathrm{BPT}){ }_{3}{ }^{3+}$ and the molar absorption coeffcient of $\mathrm{Fe}(\mathrm{BPT})_{3}{ }^{2+}, \varepsilon=2.235 \times 10^{4} \mathrm{M}^{-1}$ $\mathrm{cm}^{-1}$. incubation time extended (black dot). The phenomena showed that the reduction of $\mathrm{Fe}(\mathrm{BPT})_{3}{ }^{3+}$ by TCEP directly was very slow and the reduction could be accelerated drastically by the addition of trace amounts of AA. According to the stoichiometric reaction between $\mathrm{AA}$ and $\mathrm{Fe}(\mathrm{BPT})_{3}{ }^{3+}$ and the molar absorption coefficient of $\mathrm{Fe}(\mathrm{BPT})_{3}{ }^{2+}(22350 \mathrm{~L}$ $\left.\mathrm{mol}^{-1} \mathrm{~cm}^{-1}\right)$, the absorbance at $534 \mathrm{~nm}$ calculated should increase to 0.0223 if every AA molecule only could reduce two $\mathrm{Fe}(\mathrm{BPT}){ }_{3}{ }^{3+}$ ions. The fact was that the absorbance increased about 0.11 after incubation of the redox-cycling system at 50 ${ }^{\circ} \mathrm{C}$ for $7 \mathrm{~min}$. Obviously, the increase in the absorbance was not due to the reduction of $\mathrm{Fe}(\mathrm{BPT})_{3}{ }^{3+}$ by AA only once. In consideration of other work mentioned above, we concluded a redox-cycling system probably was formed by the introduction of AA to the solution in which the AA could be regenerated repeatedly based on the following reasons. (1) $\mathrm{Fe}(\mathrm{BPT})_{3}{ }^{3+}$, a clathrate with a redox active site at the center, was encapsulated in the nonionic micelle of TX-100. The peripheral micelle and BPT hindered negative charged TCEP with large size to collide with $\mathrm{Fe}^{3+}$ and therefore the reaction between TCEP and $\mathrm{Fe}(\mathrm{BPT})_{3}{ }^{3+}$ became very slow. (2) Compared with TCEP, the neutral AA with small size could pass through the micelle easily and $\mathrm{Fe}(\mathrm{BPT}){ }_{3}{ }^{3+}$ was reduced quickly. (3) The oxidation product, dehydroascorbic acid, is also a neutral molecule that could escape out of the micelle easily and could be reduced to AA by TCEP again. The regenerated $\mathrm{AA}$ then passed through the micelle and resulted in the reduction of more $\mathrm{Fe}(\mathrm{BPT})_{3}{ }^{3+}$ to red $\mathrm{Fe}(\mathrm{BPT})_{3}{ }^{2+}$. As shown in Figure S12 (Supporting Information), it should be noted here that the micelle of TX-100 not only effectively hindered the reaction between $\mathrm{Fe}(\mathrm{BPT})_{3}{ }^{3+}$ and TCEP but also promoted the dissolution of $\mathrm{Fe}(\mathrm{BPT}){ }_{3}{ }^{3+}$.

Colorimetric Detection of AA by the Redox-Cycling System. Figure 1B shows the absorbance at $534 \mathrm{~nm}$ (curve a in B) and color (digital photo inset in B) of the redox-cycling system response to different concentrations of AA. Compared with the absorbance calculated according to the stoichiometric reaction between $\mathrm{AA}$ and $\mathrm{Fe}(\mathrm{BPT}){ }_{3}{ }^{3+}$ (curve $\mathrm{b}$ ), the signal (curve a), after deducting the background caused by the spontaneous reaction between $\mathrm{Fe}(\mathrm{BPT})_{3}{ }^{3+}$ and TCEP, was amplified about 4.8 -fold (slope of curve a/slope of curve b), indicating every AA molecule can be averagely regenerated 3.8 times by TCEP in the redox-cycling system. Curve a in Figure $1 \mathrm{~B}$ also manifests the absorbance increases linearly with the increasing concentration of $\mathrm{AA}$ in the range from 0.05 to 1.0 $\mu \mathrm{M}$ under optimum conditions: $\mathrm{pH}, 9.6 ; \mathrm{Fe}^{3+}, 0.1 \mathrm{mM}$; BPT, $0.2 \mathrm{mM}$; TCEP, $1.5 \mathrm{mM}$; TX-100, 0.3\%; incubation time, 10 min; temperature, $50{ }^{\circ} \mathrm{C}$. The selection of these conditions are shown from Figures S3-S9 (Supporting Information). To the best of our knowledge, the proposed redox-cycling system for detecting $\mathrm{AA}$ is more sensitive than most of the existing colorimetric methods. ${ }^{19,27-30}$

Colorimetric Detection of ALP by the Redox-Cycling System. In the proposed ELISA, ALP tagged antibody was used as the labeling reagent. The sensitivity for monitoring ALP determines the sensitivity of ELISA to a certain extent. Before the application of the redox-cycling to ELISA, the redox-cycling response to different concentrations of ALP was investigated under the optimum conditions. The selection of these conditions are shown in Figures $S 10$ and S11 (Supporting Information). Figure 2 shows the absorbance and color change induced by different concentrations of ALP. The absorbance increased sharply with the increasing ALP 


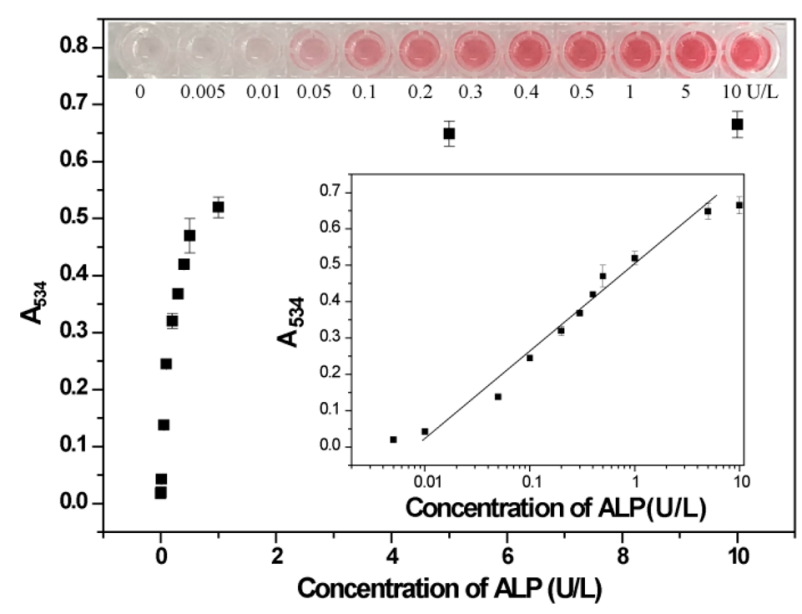

Figure 2. Absorbance at $534 \mathrm{~nm}$ and color of the redox-cycling response to different concentrations of ALP.

concentration and then became flattened at $5.0 \mathrm{U} / \mathrm{L}$. By plotting the absorbance against the logarithmic value of each concentration, a linear calibration curve $(A=0.50+0.24 \mathrm{lg}$ $C_{\mathrm{ALP}}$ ) was obtained in the range from 0.01 to $5.0 \mathrm{U} / \mathrm{L}$. The detection limit calculated to be $0.006 \mathrm{U} / \mathrm{L}$ according to the $3 \sigma$ rule. The digital photo inset in Figure 2 shows the solution changed from colorless to light red and even to deep red with the increase in ALP, which was consistent with the absorbance change. The concentration of ALP that could be visualized by the naked eye was as low as $0.01 \mathrm{U} / \mathrm{L}$. Compared with the recent developed colorimetric methods for ALP detection are listed in Table S1 (Supporting Information), the proposed method is more sensitive and simpler. ${ }^{19,20,31-37}$

Colorimetric Detection of AFP by the Redox-Cycling System. AFP is an important hepatic tumor biomarker, and the quantification of AFP plays a vital role in early clinical diagnosis. ${ }^{38}$ Here we chose AFP as a model antigen to evaluate the application of the proposed redox-cycling-based ELISA. Figure $3 \mathrm{~A}$ shows the results. With the increase in AFP, the absorbance rose sharply at first and gradually came to a standstill at $30 \mathrm{ng} / \mathrm{mL}$. The absorbance was linear with the concentration of AFP in the range from 0.01 to $5.0 \mathrm{ng} / \mathrm{mL}$ with a regression equation of $A=0.064 C_{\mathrm{AFP}}+0.050$ (inset in Figure $3 \mathrm{~A}$ ). The detection limit, $0.005 \mathrm{ng} / \mathrm{mL}$, was obtained according to the $3 \sigma$ rule. The digital photo inset in Figure $3 \mathrm{~A}$ shows that the solution became deeper and deeper with the increasing concentration of AFP. The lowest concentration of AFP that could be readily distinguished with the naked eye was less than $0.1 \mathrm{ng} / \mathrm{mL}$. Without using the redox-cycling system (no TCEP was added to the enzymatic solution), a linear range from 3 to $30 \mathrm{ng} / \mathrm{mL}$ for assay AFP with a detection limit of 1.8 $\mathrm{ng} / \mathrm{mL}$ was obtained (Figure $3 \mathrm{~B}$ ). Compared with the ALP tag or horseradish peroxidase tag-based conventional ELISA, ${ }^{36}$ the redox-cycling promoted the sensitivity about 2 orders of magnitude. The proposed ELISA is also comparable to the ELISA based on various signal amplification techniques, many other sensitive electrochemical immunoassay, fluorescence immunoassay, and even chemiluminescence immunoassay. The details are listed in Table S2 (Supporting Information)..$^{34,36,39-45}$ Besides, the proposed method can avoid a cumbersome analysis process, a labeling procedure, or sophisticated instruments.

Reproducibility, Nonspecific Adsorption, and Specificity of the Colorimetric ELISA. The reproducibility of this
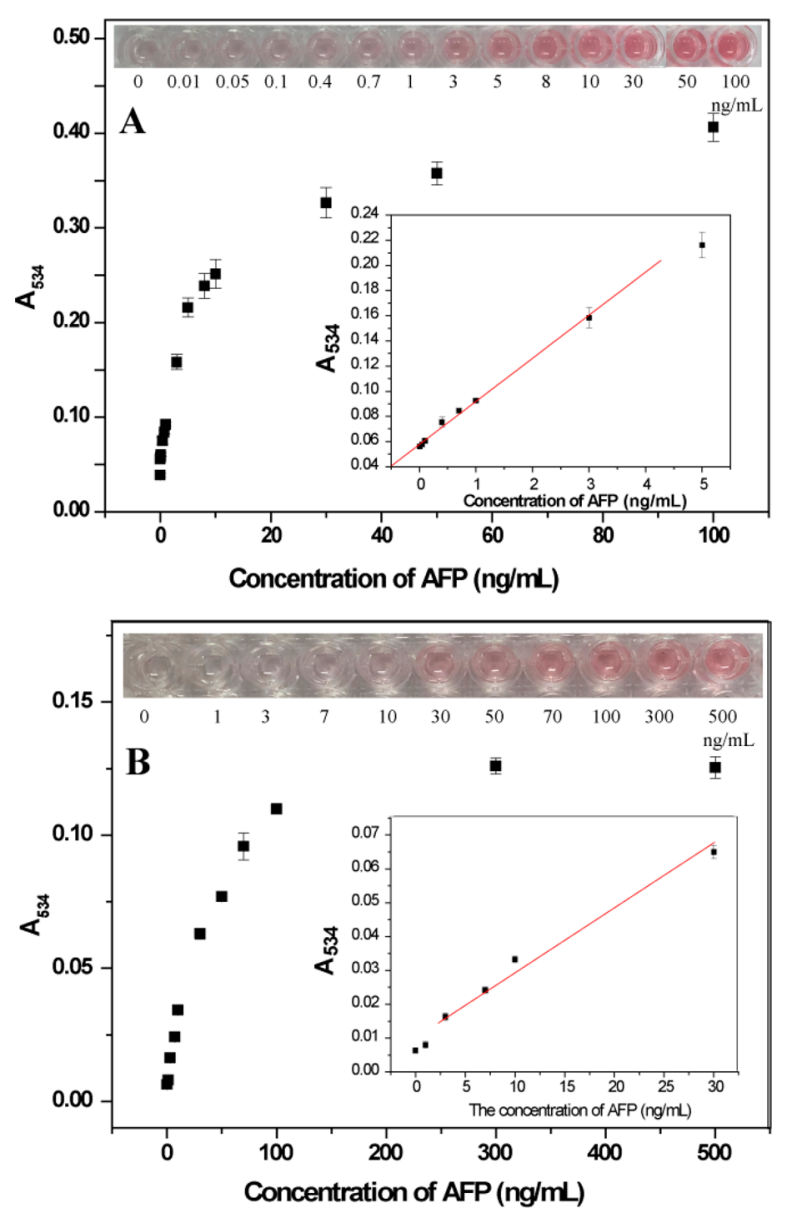

Figure 3. Absorbance at $534 \mathrm{~nm}$ and color of the redox-cycling-based ELISA (A) and ALP tag based conventional ELISA for sensing of different concentrations of AFP (B).

redox-cycling-based colorimetric ELISA was evaluated by calculating the intra- and interassay variation coefficients $(\mathrm{CVs})$. The results of intra-assay and interassay for the detection of $3 \mathrm{ng} / \mathrm{mL}$ AFP, both based on five times repetitive measurements, were $3.3 \%$ and $7.1 \%$, respectively, shown in the Figures S13 and S14 (Supporting Information). Therefore, the reproducibility of the colorimetric immunoassay was acceptable because this method avoids complicated multistep operations of biomaterials.

The nonspecific adsorption was also investigated by using the same immunoassay procedure, except that the mouse antiAFP (A2) monoclonal antibody coated polystyrene plate was replaced by the BSA coated polystyrene plate. As shown in Figure S15 (Supporting Information), when the BSA coated polystyrene plate was used as the immunoreaction surface, no obvious absorbance change can be found between $5 \mathrm{ng} / \mathrm{mL}$ AFP and the blank, while if the plate was coated by mouse antiAFP (A2) monoclonal antibody, a significant absorbance change was obtained. These results indicated the use of BSA as a blocking reagent could eliminate nonspecific adsorption effectively.

To evaluate the specificity of the developed redox-cycling system for AFP detection, we challenged this system against other usual biomarkers and proteins in human serum, including carcinoembryonic antigen (CEA), immunoglobulin $\mathrm{G}(\mathrm{IgG})$, and prostate-specific antigen (PSA). As shown in Figure S16 (Supporting Information), the interfering proteins 
caused no significant absorbance signal at $534 \mathrm{~nm}$ compared with the blank value while AFP resulted in a high response signal. In addition, the coexistence of these interfering proteins had no obvious effect on the response signal toward AFP antigen. These results indicated the proposed immunoassay had high specificity and favorable resistance to the interference.

Detection of AFP in Real Human Serum. To evaluate the proposed assay toward the target in complex biological matrix, the redox-cycling-based ELISA was performed to detect AFP in human serum samples. Before the assay, serum samples donated by three volunteers were diluted 5 times to ensure the concentration of AFP was less than $5 \mathrm{ng} / \mathrm{mL}$. Table 1 lists the

Table 1. Comparison of the Found Levels of AFP in Real Human Serum Samples by Proposed Method and Commercial AFP ELISA Kit, Respectively

\begin{tabular}{cccc} 
sample & $\begin{array}{c}\text { found by conventional } \\
\text { ELISA }\end{array}$ & $\begin{array}{c}\text { found by proposed } \\
\text { method }\end{array}$ & $\begin{array}{c}\text { relative error } \\
(\%)\end{array}$ \\
1 & $4.7 \pm 0.4$ & $5.1 \pm 0.4$ & 8.5 \\
2 & $8.2 \pm 0.7$ & $7.8 \pm 0.6$ & -2.4 \\
3 & $3.2 \pm 0.3$ & $2.9 \pm 0.3$ & -9.3 \\
\hline
\end{tabular}

quantitative and the reference value of each sample. The accuracy of the redox-cycling-based ELISA immunoassay was in accordance with the commercial AFP ELISA kit for the real sample analysis. Human serum is composed of many kinds of proteins, fats, carbohydrates, inorganic salts, small organic molecules (AA and glucose, for example), and so on. The successful AFP assay with different concentrations in human serum coming from different individuals showed that the proposed immunoassay was reliable and could eliminate the interference from protein, salt, and other small molecules.

\section{CONCLUSION}

In summary, we have developed an ultrasensitive colorimetric ELISA based on a chemical redox-cycling reaction. The redoxcycling promoted the sensitivity about 2 orders of magnitude without using sophisticated instruments. Compared with other recent reported ELISA, the redox-cycling-based ELISA possesses many other advantages: (1) since ALP-labeled antibodies are commercially available, it is easier to adapt to conventional ELISA platforms directly; (2) the proposed ELISA is very simple and easy to operate because it does not require complex synthesis of nanoparticles or labeling procedures; (3) the reaction between $\mathrm{AA}$ and $\mathrm{Fe}(\mathrm{BPT})_{3}{ }^{3+}$ is a classic colorimetric reaction which can take place in the solution, and this method has a relatively high reproducibility; (4) the amplified signal can be easily read by the naked eye, providing a fairly simple but efficient approach for ELISA. In consideration of the versatility of immunoassay, the proposed method can potentially be an effective tool for the detection of other biomarkers.

\section{ASSOCIATED CONTENT}

\section{S Supporting Information}

The Supporting Information is available free of charge on the ACS Publications website at DOI: 10.1021/acs.analchem.8b05095.

Experimental section in detail; optimization of experimental conditions, including the selection of appropriate reductant and chelating agent (Figures $\mathrm{S} 1$ and S2); concentration of TCEP, TX-100, $\mathrm{Fe}^{3+}, \mathrm{BPT}$, as well as the $\mathrm{pH}$, temperature, incubation time, the concentration of AA-p, and catalysis time (Figures S3-S11); comparison of the colorimetric assays for ALP detection (Table S1); comparison of the different methods for AFP detection (Table S2); impact of TX-100 on AA and TCEP (Figure S12); reproducibility, nonspecific adsorption, and the specificity of the proposed method for AFP detection (Figures S13-S16) (PDF)

\section{AUTHOR INFORMATION}

\section{Corresponding Authors}

*Phone: 86-535-2109133. E-mail: zhpchen@yic.ac.cn.

*Phone: 86-535-2109130. E-mail: 1xchen@yic.ac.cn.

ORCID ${ }^{\circledR}$

Zhaopeng Chen: 0000-0003-0533-3974

Lingxin Chen: 0000-0002-3764-3515

Notes

The authors declare no competing financial interest.

\section{ACKNOWLEDGMENTS}

This work was financially supported by the National Natural Science Foundation of China (Grants 21575159, 21804010, 41601525, and 41776110) and the Natural Science Foundation of Shandong Province of China (Grants ZR2014BL031, ZR2016DB07, and ZR2016BL25).

\section{REFERENCES}

(1) Asensio, L.; Gonzalez, I.; Garcia, T.; Martin, R. Food Control 2008, 19, 1-8.

(2) Brena, B. M.; Arellano, L.; Rufo, C.; Last, M. S.; Montano, J.; Cerni, E. E.; Gonzalez-Sapienza, G.; Last, J. A. Environ. Sci. Technol. 2005, 39, 3896-3903.

(3) Ambrosi, A.; Airo, F.; Merkoci, A. Anal. Chem. 2010, 82, 11511156.

(4) Liu, D.; Huang, X.; Wang, Z.; Jin, A.; Sun, X.; Zhu, L.; Wang, F.; Ma, Y.; Niu, G.; Walker, A. R. H.; Chen, X. ACS Nano 2013, 7, 5568-5576.

(5) de la Rica, R.; Stevens, M. M. Nat. Protoc. 2013, 8, 1759-1764.

(6) Lai, W.; Tang, D.; Zhuang, J.; Chen, G.; Yang, H. Anal. Chem. 2014, 86, 5061-5068.

(7) Gould, E. A.; Buckley, A.; Cammack, N. J. Virol. Methods 1985 , $11,41-48$.

(8) Draberova, E.; Stegurova, L.; Sulimenko, V.; Hajkova, Z.; Draber, P.; Draber, P. J. Immunol. Methods 2013, 395, 63-70.

(9) Shan, S.; Liu, D.; Guo, Q.; Wu, S.; Chen, R.; Luo, K.; Hu, L.; Xiong, Y.; Lai, W. J. Dairy Sci. 2016, 99, 7025-7032.

(10) Guo, Q.; Han, J.-J.; Shan, S.; Liu, D.-F.; Wu, S. S.; Xiong, Y.-H.; Lai, W.-H. Biosens. Bioelectron. 2016, 86, 990-995.

(11) Singh, A. K.; Kilpatrick, P. K.; Carbonell, R. G. Biotechnol. Prog. 1995, 11, 333-341.

(12) Lin, C. Y.; Guo, Y. J.; Zhao, M. M.; Sun, M.; Luo, F.; Guo, L. H.; Qiu, B.; Lin, Z. Y.; Chen, G. N. Anal. Chim. Acta 2017, 963, 112118.

(13) Lai, W.; Wei, Q.; Xu, M.; Zhuang, J.; Tang, D. Biosens. Bioelectron. 2017, 89, 645-651.

(14) Dhawan, S. Peptides 2002, 23, 2099-2110.

(15) Martinkova, P.; Opatrilova, R.; Kruzliak, P.; Styriak, I.; Pohanka, M. Mol. Biotechnol. 2016, 58, 373-380.

(16) Lei, C.; Xu, C.; Nouwens, A.; Yu, C. Z. J. Mater. Chem. B 2016, 4, 4975-4979.

(17) Knopp, D.; Tang, D.; Niessner, R. Anal. Chim. Acta 2009, 647, 14-30.

(18) Qu, Z.; Xu, H.; Xu, P.; Chen, K.; Mu, R.; Fu, J.; Gu, H. Anal. Chem. 2014, 86, 9367-9371. 
(19) Zhang, Z.; Chen, Z.; Wang, S.; Cheng, F.; Chen, L. ACS Appl. Mater. Interfaces 2015, 7, 27639-27645.

(20) Xianyu, Y.; Wang, Z.; Jiang, X. ACS Nano 2014, 8, 1274112747.

(21) Morikawa, M.; Naito, R.; Mita, K.; Watabe, S.; Nakaishi, K.; Yoshimura, T.; Miura, T.; Hashida, S.; Ito, E. Biophysics and physicobiology 2015, 12, 79-86.

(22) Chen, Z.; Zhang, N.; Zhuo, L.; Tang, B. Microchim. Acta 2009, 164, 311-336.

(23) Akanda, M. R.; Aziz, M. A.; Jo, K.; Tamilavan, V.; Hyun, M. H.; Kim, S.; Yang, H. Anal. Chem. 2011, 83, 3926-3933.

(24) Akanda, M. R.; Tamilavan, V.; Park, S.; Jo, K.; Hyun, M. H.; Yang, H. Anal. Chem. 2013, 85, 1631-1636.

(25) Xia, N.; Ma, F.; Zhao, F.; He, Q.; Du, J.; Li, S.; Chen, J.; Liu, L. Electrochim. Acta 2013, 109, 348-354.

(26) Liu, L.; Gao, Y.; Liu, H.; Du, J.; Xia, N. Electrochim. Acta 2014, 139, 323-330.

(27) Fan, S.; Zhao, M.; Ding, L.; Li, H.; Chen, S. Biosens. Bioelectron. 2017, 89, 846-852.

(28) Ji, D.; Du, Y.; Meng, H.; Zhang, L.; Huang, Z.; Hu, Y.; Li, J.; Yu, F.; Li, Z. Sens. Actuators, B 2018, 256, 512-519.

(29) Li, R.; An, H.; Huang, W.; He, Y. Sens. Actuators, B 2018, 259, 59-63.

(30) Wang, J.; Fang, X.; Cui, X.; Zhang, Y.; Zhao, H.; Li, X.; He, Y. Talanta 2018, 188, 266-272.

(31) Hu, Q.; Zhou, B.; Dang, P.; Li, L.; Kong, J.; Zhang, X. Anal. Chim. Acta 2017, 950, 170-177.

(32) Hu, Q.; He, M.; Mei, Y.; Feng, W.; Jing, S.; Kong, J.; Zhang, X. Talanta 2017, 163, 146-152.

(33) Zhang, H.; Ma, X.; Hu, S.; Lin, Y.; Guo, L.; Qiu, B.; Lin, Z.; Chen, G. Biosens. Bioelectron. 2016, 79, 874-880.

(34) Sun, J.; Zhao, J.; Bao, X.; Wang, Q.; Yang, X. Anal. Chem. 2018, 90, 6339-6345.

(35) Yang, J.; Zheng, L.; Wang, Y.; Li, W.; Zhang, J.; Gu, J.; Fu, Y. Biosens. Bioelectron. 2016, 77, 549-556.

(36) Xuan, Z.; Li, M.; Rong, P.; Wang, W.; Li, Y.; Liu, D. Nanoscale 2016, 8, 17271-17277.

(37) Wang, C.; Gao, J.; Cao, Y.; Tan, H. Anal. Chim. Acta 2018, 1004, 74-81.

(38) Sturgeon, C. Clin. Chem. 2002, 48, 1151-1159.

(39) Zhang, L.; Fan, C.; Liu, M.; Liu, F.; Bian, S.; Du, S.; Zhu, S.; Wang, H. Sens. Actuators, B 2018, 266, 543-552.

(40) Liu, Y.; Chen, J.; Du, M.; Wang, X.; Ji, X.; He, Z. Biosens. Bioelectron. 2017, 92, 68-73.

(41) Deng, X.; Fang, Y.; Lin, S.; Cheng, Q.; Liu, Q.; Zhang, X. ACS Appl. Mater. Interfaces 2017, 9, 3514-3523.

(42) Yang, Z.; Cao, Y.; Li, J.; Lu, M.; Jiang, Z.; Hu, X. ACS Appl. Mater. Interfaces 2016, 8, 12031-12038.

(43) Sun, J.; Hu, T.; Chen, C.; Zhao, D.; Yang, F.; Yang, X. Anal. Chem. 2016, 88, 9789-9795.

(44) Yang, T.; Li, C. M.; He, J. H.; Chen, B.; Li, Y. F.; Huang, C. Z. Anal. Chem. 2018, 90, 9966-9974.

(45) Guo, J.; Wang, J.; Zhao, J.; Guo, Z.; Zhang, Y. ACS Appl. Mater. Interfaces 2016, 8, 6898-6904. 